\title{
DRYING STUDY OF EUCALYTPTUS STAIGERIANA LEAVES BY MONITORING THE HUMIDITY OF THE DRYER DISCHARGE
}

\author{
N. P. Bragaa \\ A. Starquit ${ }^{\mathrm{a}}$, \\ M. A. Cremasco ${ }^{\mathrm{a}}$, \\ and J. O. Brito ${ }^{\mathrm{b}}$ \\ ${ }^{a}$ Universidade Estadual de Campinas \\ Departamento de Termofluidodinâmica \\ Cidade Universitária Zeferino Vaz \\ C.P 6066, Campinas, SP, Brasil \\ cremasco@feq.unicamp.br \\ ${ }^{\mathrm{b}}$ Instituto de Pesquisas e Estudos Florestais \\ ESALQ/Universidade de São Paulo \\ Av. Pádua Dias, 11 \\ C.P 530, Piracicaba, SP, Brazil.
}

\begin{abstract}
The drying phenomenon can be treated as simultaneous heat and mass transfer in both the light and heavy phases. In the present case, the phenomenon's evolution is normally observed through the heating of and moisture removal from the heavy phase. On the other hand, while the material is heating, the light phase is cooling and humidifying. The goal of the present work is to present discharge air humidification curves as a function of the drying time for Eucalyptus staigeriana leaves drying experiments. For the air humidification measurements, a dry bulb thermocouple and relative humidity transducer were installed at both the dryer inlet and outlet. The dryer was linked to a data acquisition system, which recorded the dry bulb temperature and the relative humidity with time. These data were later used to calculate the air moisture content at the dryer inlet and outlet. The data obtained by this methodology are compared with the ones from drying kinetic (moisture content removing of the heavy phase along time), acquired by the evolution of wet material weight through the use of an analytical scale.
\end{abstract}

Keywords: drying, air humidificating, Eucalyptus staigeriana.

\section{NOMENCLATURE}

Ave average value

$f(a), f(b)$ and $f(c)$ functions at each point of the material

$\mathrm{h} \quad$ intervals number

$\mathrm{H}$ enthalpy, $\mathrm{kcal} /(\mathrm{kg}$ of air)

m mass, $\mathrm{kg}$

Min minimum value

Max maximum value

MD maximum deviation value

psy psychrometry

$\mathrm{Pv}$ vapor pressure, $\mathrm{Pa}$

Rd essential oil yield, \%

SD standard deviation

$\mathrm{t}$ drying time, $\mathrm{s}$

Tbs dry bulb temperature, ${ }^{\circ} \mathrm{C}$

Tbu wet bulb temperature, ${ }^{\circ} \mathrm{C}$

Tpo dew point temperature, ${ }^{\circ} \mathrm{C}$

UR relative humidity, $\%$

V specific volume, $\mathrm{m}^{3} / \mathrm{kg}$

w.b wet basis, $\%$

W absolute humidity, $\mathrm{kg} / \mathrm{kg}$

Y ratio of humidity $(\mathrm{kg} / \mathrm{kg})$

\section{Subscripts}

ac accumulated

e equilibrium f final

fl fresh leaves

i initial

o oil

out outlet

\section{INTRODUCTION}

Drying plays an important role in almost all the fields of the consumption industries (Keey, 1978). Drying is a natural or artificial phenomenon during which a wet body diminishes gradually its water content until reaching a hygroscopic balance with the environment (Barros Filho and Grandi, 1981).

The drying environment in a drier is constituted of humid air, which is a mixture of dry air and water vapor. Dry air consists mainly of gaseous oxygen and nitrogen, with other components at lower ratios, such as: carbon dioxide, argon, neon etc. Although the mass water vapor fraction in the drying air is always less that one tenth, the presence of water vapor molecules has a strong effect on the process. Three terms related to the humidity can be used to characterize the water vapor present in the drying air: vapor pressure $(\mathrm{Pv})$, relative humidity (UR) and absolute humidity $(\mathrm{W})$. The temperatures that relate to the properties of the drying air are: dry bulb temperature (Tbs), dew point temperature (Tpo) 
and wet bulb temperature (Tbu). Two other properties are used for calculations of drying: enthalpy (h) and specific volume (v). The thermodynamic properties of both the dry air and water vapor are essential to analyze the drying process. Those properties can be calculated by means of state equations. However psychrometric charts exist, by means of which those properties can be obtained. The study of the thermodynamic properties is of essential importance in the simultaneous processes of heat and mass transfer. Generally dry bulb temperature (Tbs) and wet bulb temperature ( $\mathrm{Tbu}$ ) are measured to determine the thermodynamic state of air, as well as all other properties of the air-vapor system.

The main objective of this work is to measure curves of the relative humidity in the drier outlet and also to study the mass and energy balances during the drying process.

\section{MATERIALS AND METHODS}

The drying of leaves as well as the extraction of the essential oil from the dried leaves has been performed at the Department of ThermoFluid-Dynamics (DTF), Chemical Engineering School, State University of Campinas (Unicamp).

\section{Materials}

The studied material consists of Eucalyptus staigeriana fresh leaves, from the Experimental Station of Forest Sciences of Itatinga. Such species are native from the north of Australia, region that presents the highest essential oil yield and quality (Vitti and Brito, 1999).

\section{Equipment}

The drying process of Eucalyptus staigeriana leaves was carried out in a system insulated with rock wool and corrugated aluminum. The air was heated using four $400 \mathrm{~W}$ electrical resistances. A thermocouple type T monitored air temperature at the inlet of the dryer. A centrifugal blower supplied air to the drying bed. Air flow rates were controlled by two valves and measured by a Pitot tube. The dryer was connected to a data acquisition system as shown in Fig. 1.

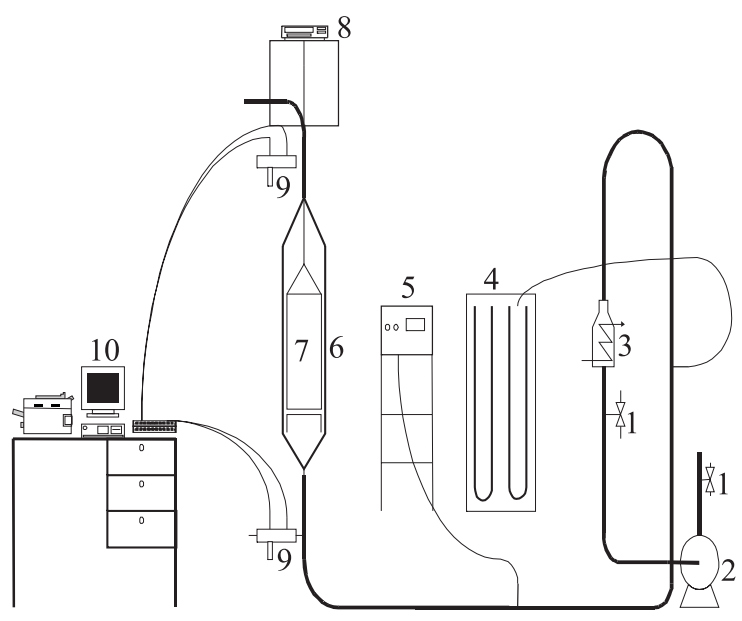

Figure 1. Drying system (Braga, 2002). 1-Drying air flow control valve; 2- Centrifugal blower; 3- Electrical heater; 4- U-shaped manometer; 5- Control panel for the drying air temperature; 6- Fixed bed dryer; 7- Drying bed; 8- Semianalytical scale; 9- Psychrometers; 10- Data acquisition system.

The acquisition system was used to obtain the data of dry bulb and wet bulb temperatures with time. These data was later used for calculations of the air moisture content at the inlet and outlet of the dryer.

The extraction of essential oil from leaves was done by cohobation in a destiller type Clevenger MA553 with capacity of $250 \mathrm{~mL}$ (manufacturer MARCONI). The mass of Eucalyptus staigeriana leaves was weighed in an analytical scale, BG400 Gehaka, with an accuracy of $0.001 \mathrm{~g}$. The extraction equipment system is represented in Fig. 2.

After extraction, the essential oil was mixed with water. As the oil presented higher density than water, it was easily separated by gravity. Residual water was removed by centrifugation (Centribio, model 80-23) and the oil was stored in a refrigerator at $5^{\circ} \mathrm{C}$.

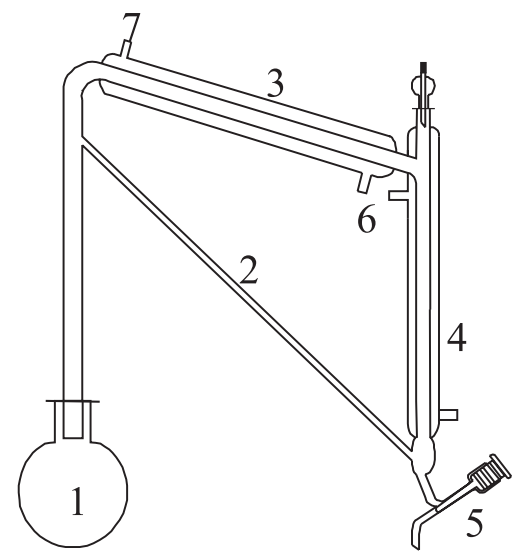

Figure 2. Clevenger extraction system. 1- $250 \mathrm{ml}$ flask containing water and E. staigeriana leaves; 
2- Return of the water from the flask;

3-Condenser; 4- Essential oil and water reservoir; 5-Device for separating water and essential oil phases; 6- Inlet cooled water;

7- Outlet cooled water.

\section{Experimental Procedure}

The air was initially heated and its temperature measured by a thermocouple in the air feed line, in which there was also one psychrometer. After the drying air temperature had reached a stable level, the leaves were arranged in a basket, which was vertically positioned in the drying bed. The leaves moisture loss was monitored by a semianalytical scale with resolution of $10^{-5} \mathrm{~kg}$. During the first 600 seconds of each run, the mass was measured at every 60 seconds, after that the measurements were made at 300 seconds intervals. To study drying by monitoring the drying air humidity and comparing the result to data obtained with the scale, the acquisition data was initiated with Eucalyptus staigeriana leaves in the drying bed. At the beginning of each run, a sample was collected for the determination of the leaves initial moisture by the standard oven method. The drying time was 7200 seconds. Before and after drying, extractions were made with fresh and dry leaves, for the determination of the essential oil yield. The mass of Eucalyptus staigeriana leaves and distillated water used for the extractions were $0.030 \mathrm{~kg}$ and $150 \mathrm{~mL}$, respectively. The essential oil yield was determined before and after drying.

The essential oil yield is the relation of the mass of oil extracted from the fresh leaves before drying and the mass of fresh leaves, as given by Eq. (1).

$$
\operatorname{Rd} \oiint_{0} w b X \frac{m_{\mathrm{o}}}{\mathrm{m}_{\mathrm{fl}}} \mathrm{u} 100
$$

\section{RESULTS AND DISCUSSION}

Two experimental runs have been carried out at drying air temperature of 40 and $60^{\circ} \mathrm{C}$, keeping constant the drying air speed at $0.56 \mathrm{~m} / \mathrm{s}$.

In the present work the properties of drying air have been calculated, using two softwares SASG 5.0 and GETPSYCHED, based on the correlations by the "American Society of Heating, Refrigerating and Air conditioning Engineer (ASHRAE)".
The mass balance during the drying process involves the monitoring of the mass loss at time intervals of $60 \mathrm{~s}$ up to $600 \mathrm{~s}$; then every 300 seconds and the absolute humidity determined by the use of the data of Tbs and UR in the dryer inlet and outlet. Based on the data presented in Tab. 1, a dimensionless curve of the humidity uptake can be constructed, as shown in Fig. 3.

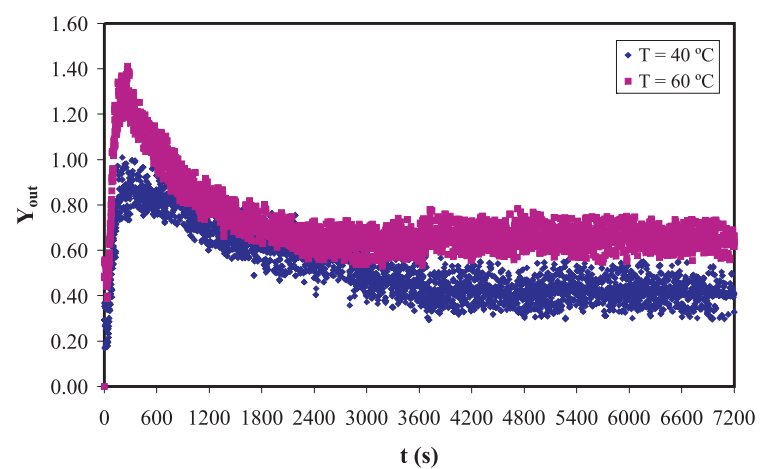

Figure 3. Drying air humidity curves in the dryer outlet.

Figure 3 shows that with higher temperature, the humidity removal is stronger and is happening mainly at the beginning of the drying. This can be seen in Fig. 3 since the peak at $60^{\circ} \mathrm{C}$ is higher than the peak at $40{ }^{\circ} \mathrm{C}$, showing that the humidity removal is faster at higher temperature. The Tbs and UR data have been used to calculate the ratio of humidity, or absolute humidity (W).

Table 1. Drying air thermodynamic properties in the drier inlet and outlet $\left(\mathrm{T}=40^{\circ} \mathrm{C}\right)$.

\begin{tabular}{|c|c|c|c|c|c|}
\hline \multicolumn{7}{|c|}{ Inlet } \\
\hline $\begin{array}{c}\mathrm{t} \\
(\mathrm{s})\end{array}$ & $\begin{array}{c}\text { Tbs } \\
\left({ }^{\circ} \mathrm{C}\right)\end{array}$ & $\begin{array}{c}\mathrm{UR} \\
(\%)\end{array}$ & $\begin{array}{c}\mathrm{W} \\
(\text { kg water/ } \\
\text { kg dry air })\end{array}$ & $\begin{array}{c}\mathrm{Tbu} \\
\left({ }^{\circ} \mathrm{C}\right)\end{array}$ & $\begin{array}{c}\mathrm{H} \\
(\mathrm{Kcal} / \\
\text { kg air })\end{array}$ \\
\hline 0 & 40.5 & 17.07 & 0.0085 & 21.1 & 62.54 \\
60 & 40.4 & 17.51 & 0.0086 & 21.2 & 62.88 \\
120 & 40.4 & 17.77 & 0.0088 & 21.3 & 63.22 \\
180 & 40.4 & 17.71 & 0.0086 & 21.2 & 63.14 \\
240 & 40.4 & 17.40 & 0.0086 & 21.1 & 62.74 \\
420 & 40.4 & 17.53 & 0.0086 & 21.2 & 62.91 \\
900 & 41.0 & 17.54 & 0.0087 & 21.5 & 64.27 \\
1200 & 40.6 & 17.61 & 0.0089 & 21.3 & 63.46 \\
2100 & 41.1 & 17.41 & 0.0087 & 21.6 & 64.32 \\
3600 & 41.0 & 17.84 & 0.0091 & 21.6 & 64.67 \\
6000 & 40.5 & 18.13 & 0.0089 & 21.4 & 63.91 \\
6600 & 40.6 & 18.49 & 0.0089 & 21.6 & 64.61 \\
6900 & 40.2 & 18.18 & 0.0089 & 21.3 & 63.29 \\
7200 & 40.3 & 18.51 & 0.0090 & 21.4 & 63.94 \\
\hline
\end{tabular}




\begin{tabular}{|c|c|c|c|c|c|}
\hline \multicolumn{5}{|c|}{ Outlet } \\
\hline 0 & 38.6 & 20.69 & 0.0096 & 21.1 & 62.69 \\
60 & 38.0 & 25.46 & 0.0111 & 22.2 & 66.72 \\
120 & 37.8 & 25.76 & 0.0116 & 22.1 & 66.55 \\
180 & 37.8 & 27.18 & 0.0117 & 22.5 & 68.15 \\
240 & 37.5 & 26.97 & 0.0116 & 22.2 & 67.11 \\
420 & 37.4 & 27.28 & 0.0115 & 22.3 & 67.19 \\
900 & 37.7 & 26.39 & 0.0113 & 22.2 & 66.99 \\
1200 & 38.0 & 25.48 & 0.0111 & 22.2 & 66.75 \\
2100 & 38.6 & 23.99 & 0.0108 & 22.1 & 66.57 \\
3600 & 38.9 & 22.99 & 0.0105 & 22.0 & 66.14 \\
6000 & 39.0 & 22.75 & 0.0105 & 22.0 & 66.10 \\
6600 & 38.8 & 23.17 & 0.0105 & 22.0 & 66.10 \\
6900 & 39.1 & 22.67 & 0.0105 & 22.0 & 66.25 \\
7200 & 38.9 & 23.01 & 0.0105 & 22.0 & 66.16 \\
\hline
\end{tabular}

To obtain the curves presented in Fig. 4, the psychrometric data have been integrated using the Simpson's rule.

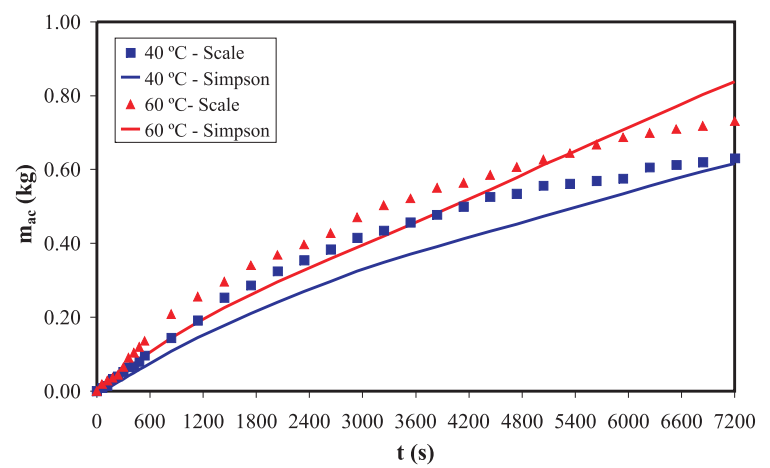

Figure 4. Comparison of the accumulated loss curves of water from analytical scale and from psychrometry (Simpson's rule).

Figure 4 points out a reasonable agreement between the two methods for the determination of the accumulated loss of water. The increase of the linearity of the mass loss as function of the time with the increment of the temperature of the drying air can be observed.

The difference between the two mass balances might be due to the condensation of the vapor present in the gaseous phase.

The phenomenon appears when evaporated water, carried by the hot air, encounters colder layers in the drying bed. If the difference between the gaseous and solid phase temperature is sufficient to reduce the vapor temperature to its dew point, part of this vapor will condense on the drier walls. In those conditions, air reaches saturation. The difference between the absolute humidity of air before and after saturation is the measure of the amount of condensed vapor. This phenomenon was observed at the temperature of $60^{\circ} \mathrm{C}$. Another justification might be the precision of the measure instruments for dry bulb temperature and relative humidity, which is $2 \%$ at $25^{\circ} \mathrm{C}$ (it is an indirect measure, so the precision can be a little higher or lower). For the analytical scale the precision is $0.2 \%$ (directly measured). According to those data, the error is bigger for the measures with the psychrometry.

The values obtained at the end of the drying are listed in Tab. 2.

Table 2. Summarized results for each drying run.

\begin{tabular}{|c|c|c|c|c|c|c|}
\hline $\begin{array}{c}\mathrm{T} \\
\left({ }^{\circ} \mathrm{C}\right)\end{array}$ & $\begin{array}{c}\mathrm{UR}_{\mathrm{e}} \\
(\%)\end{array}$ & $\begin{array}{c}\mathrm{W}_{\mathrm{e}} \\
(\mathrm{kg} / \mathrm{kg})\end{array}$ & $\begin{array}{c}\mathrm{Rd}_{\mathrm{i}} \\
(\%)\end{array}$ & $\begin{array}{c}\mathrm{Rd}_{\mathrm{f}} \\
(\%)\end{array}$ & $\begin{array}{c}\mathrm{m}_{\mathrm{ac}} \\
(\mathrm{scale}) \\
(\mathrm{kg})\end{array}$ & $\begin{array}{c}\mathrm{m}_{\mathrm{ac}} \\
(\mathrm{psy}) \\
(\mathrm{kg})\end{array}$ \\
\hline 40 & 17.07 & 0.0085 & 1.77 & 2.54 & 0.6308 & 0.6162 \\
\hline 60 & 5.11 & 0.0064 & 1.77 & 2.59 & 0.7310 & 0.8378 \\
\hline
\end{tabular}

As can be seen in Tab. 2, the essential oil yield for dried leaves raised to almost twice its value for fresh leaves. However, as the drying temperature increased, there is no significant raise of the essential oil yield, contrary to the results obtained for the drying of Eucalyptus citriodora leaves (Braga, 2002).

The uncertainty analyses of the results are listed in Tab. 3.

Uncertainty analysis of the final results between $\mathrm{Y}_{\text {out }}$ and $\mathrm{m}_{\mathrm{ac}}$ are: at $40^{\circ} \mathrm{C}(\mathrm{SD}=0.0103)$; at $60^{\circ} \mathrm{C}(\mathrm{SD}=0.0755)$.

The average and maximum deviations between "scale" and "Simpson" results from Fig. 4 are 0.0528 and $0.0434\left(40^{\circ} \mathrm{C}\right), 0.0468$ and 0.0531 $\left(60^{\circ} \mathrm{C}\right)$, respectively.

Table 3. Uncertainty analysis for $Y_{\text {out }}$ and Simpson rule.

\begin{tabular}{|c|c|c|c|c|}
\hline \multirow{2}{*}{} & \multicolumn{2}{|c|}{$\mathrm{Y}_{\text {out }}$} & \multicolumn{2}{c|}{ Simpson rule } \\
\cline { 2 - 5 } & $40^{\circ} \mathrm{C}$ & $60^{\circ} \mathrm{C}$ & $40^{\circ} \mathrm{C}$ & $60^{\circ} \mathrm{C}$ \\
\hline Ave & 0.3624 & 0.4397 & 0.0193 & 0.0214 \\
\hline MD & 0.5333 & 0.7082 & 0.0093 & 0.0122 \\
\hline SD & 0.1525 & 0.1365 & 0.0044 & 0.0046 \\
\hline
\end{tabular}

\section{CONCLUSIONS}

It has been shown that temperature influences the linearity of the mass loss in function of the drying time, as a consequence of the increase of the water removal rate.

Note also that the humidity removal of Eucalyptus staigeriana leaves takes place mainly during the 300 initial seconds of the drying, as can 
be seen in Fig. 3. The condensation phenomenon of the vapor present in the gaseous phase on the dryer walls is one of the factors that might explain the difference in the mass balances from psychrometric data and from analytical scale data. Another factor might be the difference of precision in the acquisition from the psychrometry and from the scale. Uncertainty analysis shows that precision of the measure instruments decrease with the increase in temperature. Finally, it has been shown that drying the leaves leads to a significant raise in the essential oil yield.

\section{REFERENCES}

Barros Filho, S. A., Grandi, A., 1981, Processo de secagem e automatização. Cerâmica, Vol. 27, No. 133, pp. 37-44.

Braga, N. P., 2002, Influência da secagem no rendimento e na composição do óleo essencial das folhas de Eucalyptus citriodora. Master Dissertation, Unicamp, Campinas, SP (in Portuguese).

Keey, R. B., 1978, Introduction to Industrial Drying Operations. Oxford: Pergamon Press.

Vitti,A. M. S.; Brito, J. O., 1999, Avaliação do rendimento e do teor de citronelal do óleo essencial de procedências e raças locais de Eucalyptus citriodora, Scientia Florestalis, No. 56, pp. 145-154 (in Portuguese). 